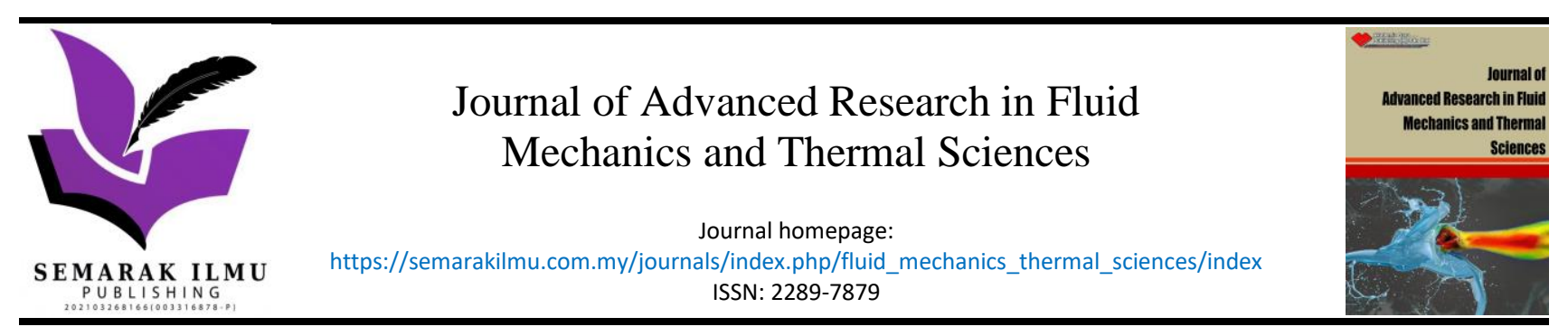

\title{
Magnetohydrodynamic Flow Past a Nonlinear Stretching or Shrinking Cylinder in Nanofluid with Viscous Dissipation and Heat Generation Effect
}

\author{
Mahani Ahmad Kardri ${ }^{1,2, *}$, Norfifah Bachok ${ }^{2,3}$, Norihan Md. Arifin ${ }^{2}$, Fadzilah Md. Ali ${ }^{2}$, Yong Faezah \\ Rahim $^{3}$ \\ Faculty of Computer and Mathematical Sciences, Universiti Teknologi MARA, Perak Branch, Tapah Campus, 35400 Tapah Road, Perak, Malaysia \\ Department of Mathematics and Institute for Mathematical Research, University Putra Malaysia, 43400 UPM Serdang, Selangor, Malaysia \\ Centre of Foundation Studies for Agriculture Sciences, Universiti Putra Malaysia, 43400 UPM Serdang, Selangor, Malaysia
}

\section{ARTICLE INFO ABSTRACT}

Article history:

Received 24 June 2021

Received in revised form 3 November 2021

Accepted 15 November 2021

Available online 11 December 2021

\section{Keywords:}

Dual solutions; heat generation; magnetohydrodynamic; nanofluid; stretching or shrinking cylinder

\begin{abstract}
The Tiwari-Das model is used to investigate magnetohydrodynamic stagnation point flow and heat transfer past a nonlinear stretching or shrinking cylinder in nanofluid with viscous dissipation and heat generation using. The partial differential equations, also known as governing equations, were reduced to nonlinear ordinary differential equations using similarity transformation. MATLAB with the bvp4c solver is used for numerical computing. The controlling parameter, such as nanoparticle volume fraction, magnetic, curvature, nonlinear, radiation, and heat generation parameters, as well as Eckert and Grashof numbers, influence the skin friction coefficient, heat transfer rate, velocity, and temperature profiles. The results are presented as graphs to show the influence of the variables studied. In some circumstances of stretching and shrinking cases, dual solutions can be obtained.
\end{abstract}

\section{Introduction}

The study of boundary layer flow and heat transfer with the presence of nanoparticles was getting exciting a few years back from the study in a nanofluid to hybrid nanofluids. The exploration in this field of study has become tremendous among researchers to study the benefit that can gain from the existence of nanofluids in fluid flow behavior and heat transfer in various applications such as the importance of heat transfer at high velocities in rocket engines and blades of the gas turbine. Crane [1] was the one who initiates the study on boundary layer flow due to a stretching cylinder. His study then continued by Wang [2] with observation on the fluid flow. Ishak et al., [3] added the effect of magnetohydrodynamic (MHD), and uniform suction or blowing [4]. Ishak and Nazar [5] observe the laminar boundary layer flow problem. Various effects have been considered in this area of studies including prescribed surface heat flux [6], slip flow [7-8], and suction or blowing and radiation [9]. A few that can be listed here for shrinking case study are in suction near a stagnation point [10], unsteady viscous flow [11-12], mixed convection flow [13], and stability analysis [14]. Besides that,

\footnotetext{
* Corresponding author.

E-mail address: mahan702@uitm.edu.my
}

https://doi.org/10.37934/arfmts.90.1.102114 
the study on stagnation point flow over stretching or shrinking cylinder examined by Najib et al., [15] and Merkin et al., [16].

The limitation in enhancing the performance of heat transfer is the low thermal conductivity fluids such as in water and oils. So, to overcome this problem, the researcher started to innovate solid particles in the base fluid (nanofluids) in the range of sizes 10-50 nm which performs better than water and oil in thermal conductivity, for example, Copper (Cu). The higher thermal conductivity of nanoparticles will increase the heat transfer for low Rayleigh numbers [17]. Qasim et al., [18] are one of the pioneers in the study of stretching cylinder in a nanofluid. They consider the MHD slip flow in ferrofluid with prescribed heat flux. A similar problem of the study was then continued by Imtiaz et al., [19] in Casson nanofluid, with mixed convection flow along with convective boundary conditions. Later, some researchers make some observations on the other effects such as thermal radiation with thermal conductivity in Williamson nanofluid [20], thermal radiation and chemical reaction in Maxwell nanofluid [21], thermal and velocity slip effects with viscous dissipation, and Joule heating [22] and the latest research on nonlinear MHD hybrid nanofluid [23]. A study on stretching or shrinking cylinder in nanofluid can be seen from the paper by Omar et al., [24], Abu Bakar et al., [25] and Adnan et al., [26]. They conclude that a unique solution exists for the stretching case, meanwhile dual solutions exist for a shrinking case.

As the study of boundary layer flow and heat transfer on a cylinder in nanofluid keep growing, several studies also have been done in shrinking cylinder case, but not as much as in stretching cylinder. We noticed the unsteady problem using Buongiorno's Model past a permeable shrinking cylinder has been discussed by Zaimi et al., [27]. They discovered that suction could contribute to higher results in skin friction coefficient, Nusselt, and Sherwood numbers. Conversely will decrease with the rises in the unsteadiness parameter. Besides that, dual solutions exist for a certain range of suction and unsteadiness parameters. Recently, the trend of study in a nanofluid moving to hybrid nanofluid and can be found in the paper by Waini et al., [28] and Khashi'ie et al., [29].

This study was conducted as we were motivated to extend the problem by Ullah et al., [30] which they studied MHD flow of Casson fluid along with a nonlinear stretching cylinder with viscous dissipation and heat generation or absorption, to shrinking case in nanofluid using Tiwari-Das model. We investigate the problem of MHD stagnation point flow past a nonlinear stretching or shrinking cylinder with the effect of viscous dissipation and heat generation. The advantage of using Tiwari Das model (single-phase model) is that the fluid, velocity, and temperature are taken as the same because the slip mechanisms are ignored. Therefore, the model is much simpler and easier to solve numerically. To the best of our knowledge, this problem still new, and no such problem have been done by any researchers.

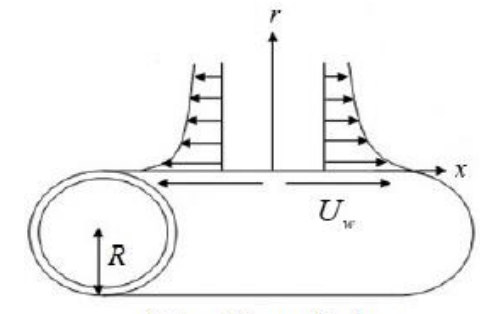

a) Stretching cylinder

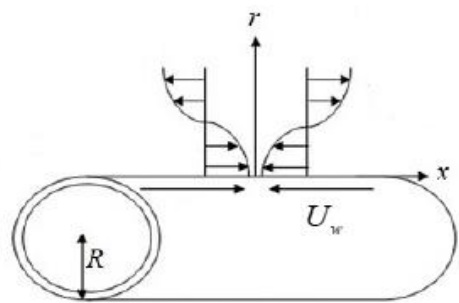

b) Shrinking cylinder

Fig. 1. Physical model and coordinate system 


\section{Mathematical analysis}

Consider a steady, two-dimensional, incompressible nanofluid stagnation point flow formed by a nonlinear stretching or shrinking cylinder with the effects of viscous dissipation and heat generation in the presence of a magnetic field. The cylinder is stretched or shrink with a free stream velocity of $U_{\infty}(x)=c x^{n}$, where $c>0$ and $c<0$ are the stretching and shrinking constants, respectively, with constant $n \neq 1$ corresponds to nonlinear stretching or shrinking cylinder with radius $R$. Meanwhile, $U_{w}(x)=a x^{n}$ where $a$ is a positive constant, represents the external velocity. The $x$-axis is taken along to the cylinder's axis, whereas the $r$-axis is measured in the radial direction.

In the radial direction, a transverse dimensionless magnetic field $B(x)=B_{0} x^{\frac{n-1}{2}}$, with constant $B_{0}$, is applied. Furthermore, it is assumed that the cylinder's surface is heated by temperature $T_{w}(x)=T_{\infty}+T_{0} x^{2 n-1}$, where $T_{0}$ is a reference temperature, $T_{\infty}$ is the temperature in the free stream and $Q(x)=Q_{0} x^{n-1}$ is the dimensionless heat generation. The governing equations, as well as the continuity equation, are given below [30-31]

$$
\begin{aligned}
& \frac{\partial(r u)}{\partial x}+\frac{\partial(r v)}{\partial r}=0, \\
& u \frac{\partial u}{\partial x}+v \frac{\partial u}{\partial r}=U_{\infty} \frac{d U_{\infty}}{d x}+\frac{\mu_{n f}}{\rho_{n f}}\left(\frac{\partial^{2} u}{\partial r^{2}}+\frac{1}{r} \frac{\partial u}{\partial r}\right)+\frac{\sigma B^{2}}{\rho_{n f}}\left(U_{\infty}-u\right)+g \beta_{T}\left(T-T_{\infty}\right) \\
& u \frac{\partial T}{\partial x}+v \frac{\partial T}{\partial r}=\alpha_{n f}\left(\frac{\partial^{2} T}{\partial r^{2}}+\frac{1}{r} \frac{\partial T}{\partial r}\right)-\frac{1}{\left(\rho C_{p}\right)_{n f}} \frac{\partial q_{r}}{\partial r}+\frac{\mu_{n f}}{\left(\rho C_{p}\right)_{n f}}\left(\frac{\partial u}{\partial r}\right)^{2}+\frac{\sigma B^{2} u^{2}}{\left(\rho C_{p}\right)_{n f}} \\
& +\frac{Q}{\left(\rho C_{p}\right)_{n f}}\left(T-T_{\infty}\right)
\end{aligned}
$$

The boundary conditions are:

$u=U_{w}, \quad v=0, \quad T=T_{w}=T_{\infty}+T_{0} x^{2 n-1}, \quad$ at $\quad r=R$,

$u \rightarrow U_{\infty}, \quad T \rightarrow T_{\infty}, \quad$ as $r \rightarrow \infty$,

where $u$ and $v$ are the velocity components along the $x$-axes and $r$-axes, $T$ is the fluid temperature, $\sigma$ is the electrically conductivity, $g$ is the gravitational force due to acceleration, and $\beta_{T}$ is the volumetric coefficient of thermal expansion.

Meanwhile, the formula for the nanofluid variables are [32]:

$$
\begin{array}{lc}
\mu_{n f}=\frac{\mu_{f}}{(1-\varphi)^{2.5}}, & \rho_{n f}=(1-\varphi) \rho_{f}+\varphi \rho_{s}, \\
\frac{k_{n f}}{k_{f}}=\frac{k_{s}+2 k_{f}-2 \varphi\left(k_{f}-k_{s}\right)}{k_{s}+2 k_{f}+\varphi\left(k_{f}-k_{s}\right)}, & \left(\rho C_{p}\right)_{n f}=(1-\varphi)\left(\rho C_{p}\right)_{f}+\varphi\left(\rho C_{p}\right)_{s}
\end{array}
$$

The dynamic viscosity, thermal diffusivity, density, heat capacity and thermal conductivity of the nanofluid are given by $\mu_{n f}, \alpha_{n f}, \rho_{n f},\left(\rho C_{p}\right)_{n f}$ and $k_{n f}$, with $\varphi$ is the nanoparticle volume fraction, $k_{f}$ 
and $k_{s}$ are the thermal conductivities of the fluid and solid fractions, $\rho_{f}$ and $\rho_{s}$ are the densities of the fluid and solid fractions, respectively and $C_{p}$ is the heat capacity of the fluid.

The governing Eq. (2) and (3) subject to the boundary condition Eq. (4) can be simplified by using the similarity transformation:

$\eta=\frac{r^{2}-R^{2}}{2 R}\left(\frac{c}{v_{f}}\right)^{\frac{1}{2}} x^{\frac{n-1}{2}}, \quad \psi=\left(c v_{f}\right)^{\frac{1}{2}} x^{\frac{n+1}{2}} R f(\eta), \quad \theta(\eta)=\frac{T-T_{\infty}}{T_{w}-T_{\infty}}$,

where $\eta$ is the similarity variable, $v_{f}$ is the base fluid's kinematic viscosity, and $\psi$ is the stream function defined as $u=\frac{1}{r} \frac{\partial \psi}{\partial r}$ and $v=-\frac{1}{r} \frac{\partial \psi}{\partial x}$, which identically satisfies Eq. (1). The boundary condition Eq. (4) at $r=R$ will be reduced to the boundary condition at $\eta=0$, which is easier to compute numerically.

Subject to the boundary conditions, Eq. (4), we get the following reduced nonlinear ordinary differential equations by substitute Eq. (6) into Eq. (2) and (3):

$$
\begin{aligned}
& \frac{1}{(1-\varphi)^{2.5}\left(1-\varphi+\varphi \rho_{s} / \rho_{f}\right)}\left[(1+2 \gamma \eta) f^{\prime \prime \prime}+2 \gamma f^{\prime \prime}\right]+\left(\frac{n+1}{2}\right) f f^{\prime \prime} \\
& \quad+\frac{M}{\left(1-\varphi+\varphi \rho_{s} / \rho_{f}\right)}\left(1-f^{\prime}\right)-n f^{\prime 2}+G r \theta+n=0 \\
& \frac{1}{1-\varphi+\varphi\left(\rho C_{p}\right)_{s} /\left(\rho C_{p}\right)_{f}}\left[\frac{1}{P r}\left(\frac{k_{n f}}{k_{f}}+\frac{4}{3} R d\right)\left[(1+2 \gamma \eta) \theta^{\prime \prime}+\gamma \theta^{\prime}\right]+\frac{1}{P r} \frac{k_{n f}}{k_{f}} \gamma \theta^{\prime}\right. \\
& \left.+\frac{1}{(1-\varphi)^{2.5}} E c(1+2 \gamma \eta) f^{\prime \prime 2}+M E c f^{\prime 2}+\Phi \theta\right]+\left(\frac{n+1}{2}\right) f \theta^{\prime}-(2 n-1) f^{\prime} \theta \\
& =0
\end{aligned}
$$

subject to the boundary conditions

$$
\begin{array}{lll}
f(0)=0, & f^{\prime}(0)=\varepsilon, & \theta(0)=1, \\
f^{\prime}(\eta) \rightarrow 1, & \theta(\eta) \rightarrow 0, & \text { as } \quad \eta \rightarrow \infty,
\end{array}
$$

where $M=\frac{\sigma B_{0}{ }^{2}}{\rho_{f} c}$ is the magnetic parameter, $\gamma=\left(\frac{v_{f} x^{1-n}}{c R^{2}}\right)^{\frac{1}{2}}$ is the curvature parameter, $\operatorname{Pr}=\frac{v_{f}}{\alpha_{f}}$ is the Prandtl number, $E c=\frac{U_{\infty}{ }^{2}}{\left(C_{p}\right)_{f}\left(T_{w}-T_{\infty}\right)}$ is the Eckert number, $G r=\frac{g \beta_{T} T_{0}}{c^{2}}$ is the Grashof number, $\Phi=$ $\frac{Q_{0}}{\left(\rho C_{p}\right)_{f} c}$ is the heat generation parameter $(\Phi>0)$ and $\varepsilon=\frac{a}{c}$ is the stretching or shrinking parameter with $\varepsilon>0$ for stretching case and $\varepsilon<0$ for shrinking case.

Using the Roseland approximation for thermal radiation, we get $q_{r}=-\frac{4 \sigma^{*}}{3 k^{*}} \frac{\partial T^{4}}{\partial r}=-\frac{16 \sigma^{*} T_{\infty}{ }^{3}}{3 k^{*}} \frac{\partial T}{\partial r}$ and the radiation parameter, $R d=\frac{4 \sigma^{*} T_{\infty}{ }^{3}}{k^{*} k_{f}}$, where $\sigma^{*}$ stands for Stefan Boltzman constant and $k^{*}$ for the mean absorption coefficient.

The physical quantities of interest are the skin friction coefficient $C_{f}$ and local Nusselt number $N u_{x}$ can be expressed as 


$$
C_{f}=\frac{\tau_{w}}{\rho_{f} U_{\infty}^{2}}, \quad \quad N u_{x}=\frac{x q_{w}}{k_{f}\left(T_{w}-T_{\infty}\right)},
$$

where the surface shear stress $\tau_{w}$ and the surface heat flux $q_{w}$ are

$$
\tau_{w}=\mu_{n f}\left(\frac{\partial u}{\partial r}\right)_{r=R}, \quad q_{w}=-k_{n f}\left(\frac{\partial T}{\partial r}\right)_{r=R}
$$

Using the similarity variable Eq. (6), we obtain

$$
C_{f} R e_{x}^{\frac{1}{2}}=\frac{1}{(1-\varphi)^{2.5}} f^{\prime \prime}(0), \quad \quad N u_{x} R e_{x}{ }^{-\frac{1}{2}}=-\frac{k_{n f}}{k_{f}} \theta^{\prime}(0)
$$

where $R e_{x}=\frac{U_{\infty} x}{v_{f}}$ is the local Reynolds number.

\section{Results analysis}

The results were obtained by performing numerical computing Eq. (7) and (8) along with the boundary condition Eq. (9) using MATLAB bvp4c after completely reducing the governing equations from partial differential equations to nonlinear ordinary differential equations. Prandtl $\operatorname{Pr}=6.2$ (water), nanoparticle volume fraction $\varphi=0.1$, curvature parameter $\gamma=0.4$, magnetic parameter $M=0.3$, nonlinear parameter $n=2$, radiation parameter $R d=3$, heat generation parameter $\Phi=$ 0.1 , Eckert number $E c=0.3$ and Grashof number $G r=0.3$ are the repeatedly chosen values. The nanoparticle volume fraction tested in the range of 0 to $0.2(0<\varphi<0.2)$ for three types of nanofluid named Copper $(\mathrm{Cu})$, Titania $\left(\mathrm{TiO}_{2}\right)$, and Alumina $\left(\mathrm{Al}_{2} \mathrm{O}_{3}\right)$. The thermophysical properties of nanoparticles and based fluid are shown in Table 1. Comparison of the present results obtained with the previous literature has been made to ensure the results are valid and meaningful to proceed in solving the problem studied as can be seen in Table 2 .

Table 1

Thermophysical properties [32]

\begin{tabular}{lllll}
\hline Physical properties & Water & $\mathrm{Cu}$ & $\mathrm{Al}_{2} \mathrm{O}_{3}$ & $\mathrm{TiO}_{2}$ \\
\hline$\rho\left(\mathrm{kg} / \mathrm{m}^{3}\right)$ & 997.1 & 8933 & 3970 & 4250 \\
$C_{p}(\mathrm{~J} / \mathrm{kgK})$ & 4179 & 385 & 765 & 686.2 \\
$k(W / \mathrm{mK})$ & 0.613 & 400 & 40 & 8.9538 \\
\hline
\end{tabular}

Figure 2 depicts the effects of nanoparticle volume fraction $\varphi$ on shear stress and local heat flux. Increases nanoparticle volume fraction $\varphi$ resulted to decrease the range of solution for shear stress and local heat flux and found to raise both values when $\varphi>-1.2$. This situation happened because the aggregation of Copper nanoparticles is rising as well as the viscosity of the nanofluid. The region for no solution is, $\varepsilon<\varepsilon_{c}$, unique solutions is, $\varepsilon>0.5$ and dual solutions is, $\varepsilon_{c}<\varepsilon \leq 0.5$. The approximation of boundary layer breaks down at $\varepsilon=\varepsilon_{c}$ as no further results can be reached since boundary layer separation occurred from the surface. Figure 3 shows the existence of magnetic parameter $M$ and curvature parameter $\gamma$ that can contribute to the higher value of shear stress and widen the range of solution. These explain that cylinder surface $(\gamma>0)$ increased the range of solutions obtains compared to a flat plate $(\gamma=0)$. Meanwhile, magnetic parameter plays an 
important role as it gives a resistive force on nanoparticles that function as a drag-like force which produces flow retardation impact and contributes to higher velocity gradient.

\section{Table 2}

Comparison values of $f^{\prime \prime}(0)$ for stretching or shrinking cylinder when $\operatorname{Pr}=1, n=1$, $\varphi=\gamma=M=G r=R d=E c=\Phi=0$ for various of $\varepsilon$

\begin{tabular}{llll}
\hline$\varepsilon$ & \multicolumn{3}{c}{$f^{\prime \prime}(0)$} \\
\cline { 2 - 4 } & Wang [33] & Bhatti et al., [34] & Present results \\
\hline 5 & -10.26475 & -10.26474931 & -10.26474930 \\
2 & -1.88731 & -1.88730667 & -1.88730666 \\
1 & 0 & 0 & 0 \\
0.5 & 0.71330 & 0.71329495 & 0.71329494 \\
0 & 1.232588 & 1.23258765 & 1.23258763 \\
-0.5 & 1.49567 & 1.49566976 & 1.49566973 \\
-1 & 1.32882 & 1.32881688 & 1.32881684 \\
-1.15 & 1.08223 & 1.08223117 & 1.08223113 \\
1.2465 & 0.55430 & 0.58428167 & 0.58428139 \\
\hline
\end{tabular}

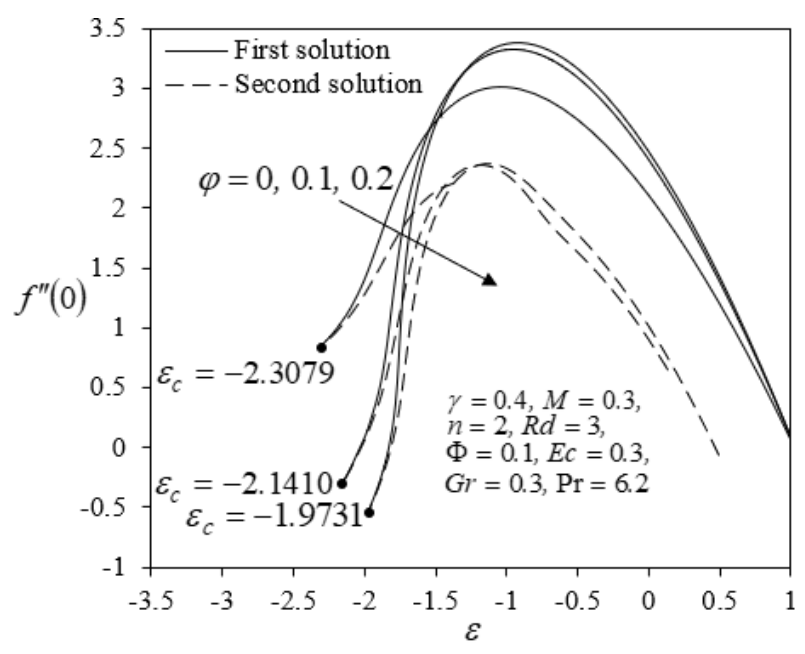

(a) Shear stress for different $\varphi$

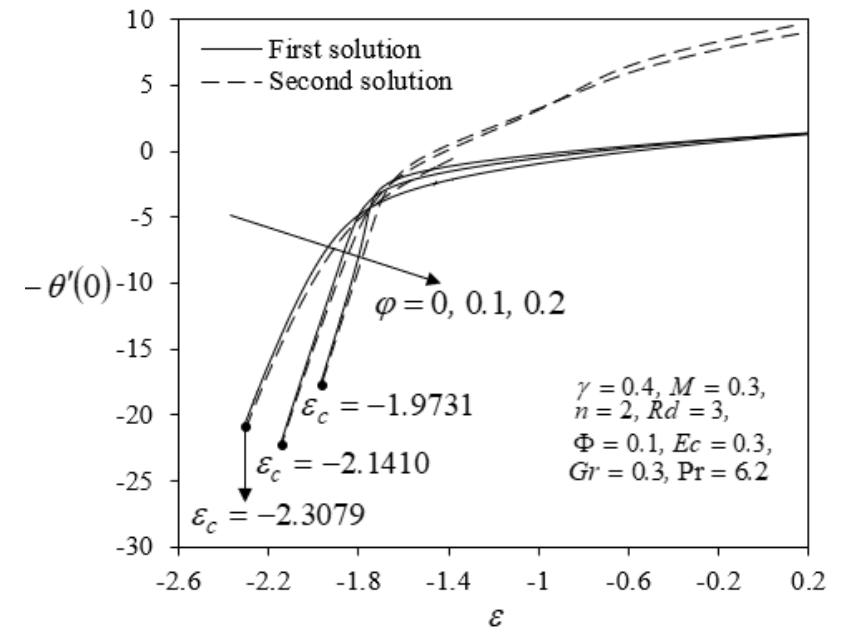

(b) Local heat flux for different $\varphi$

Fig. 2. Variation of shear stress and local heat flux with $\varepsilon$ for some values of $\varphi$

The nonlinear parameter $n$ effects discovered in Figure 4 with increases $n$ value will decrease the local heat flux initially, conversely increase eventually. The higher value of $n$ will decrease the range of solution. Figure 4 also shows the performance of the heat generation parameter $\Phi$ and Eckert number $E c$ on the local heat flux. The increment of $E c$ and $\Phi$, improves the heat transfer at a certain range for Eckert number $E c, \varepsilon_{c}<\varepsilon \leq-1.8$ and for heat generation parameter $\Phi, \varepsilon_{c}<\varepsilon \leq-1.85$. The range of solution seen to be increase with increases of $E c$ and $\Phi$. This reveals a higher Eckert number $E c$ in the fluid flows generated heat due to the viscous thermal dissipation dominates the fluid temperature. 


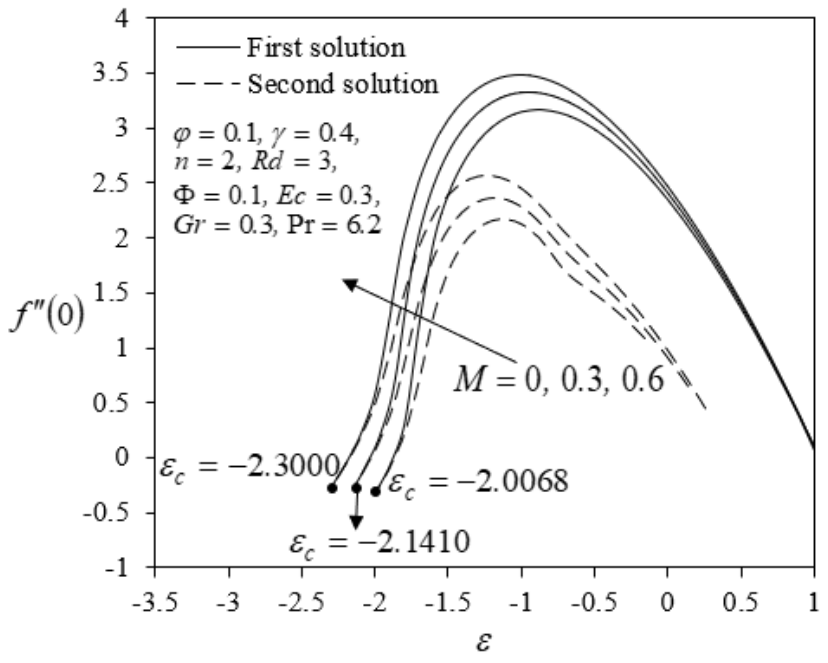

(a) Shear stress for different $M$

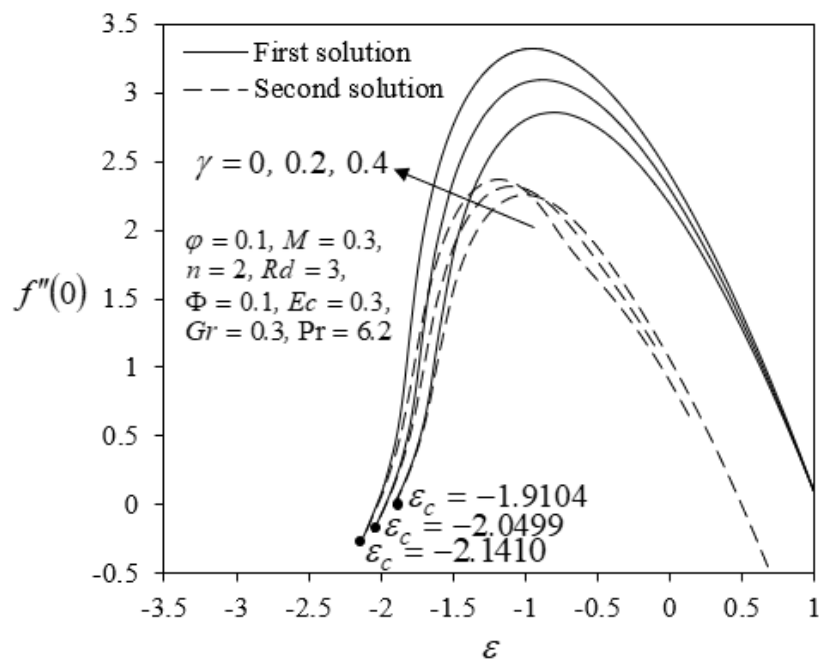

(b) Shear stress for different $\gamma$

Fig. 3. Variation of shear stress with $\varepsilon$ for some values of $M$ and $\gamma$

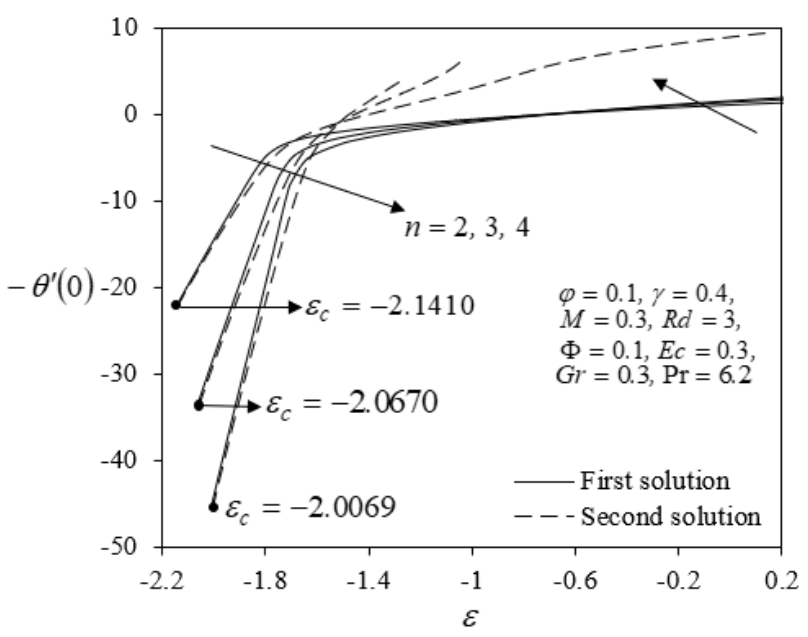

(a) Local heat flux for different $n$

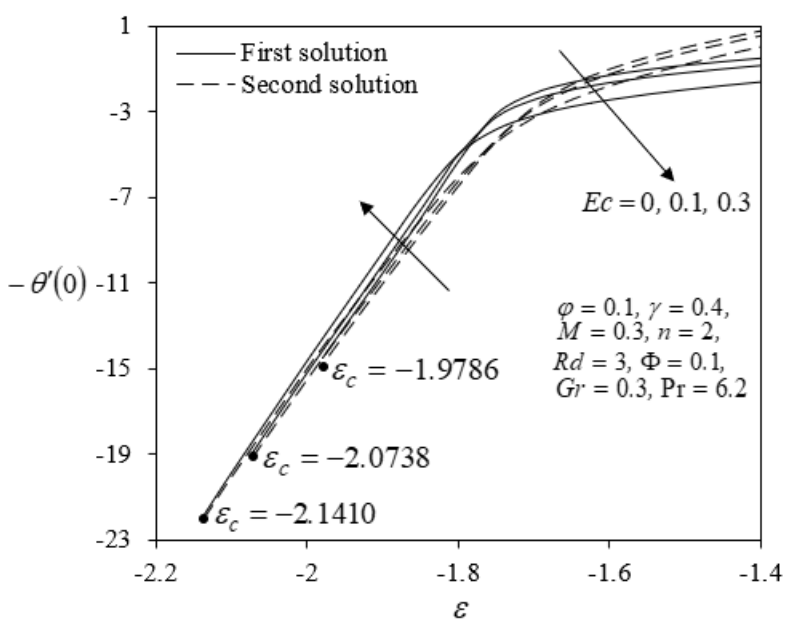

(b) Local heat flux for different $E c$

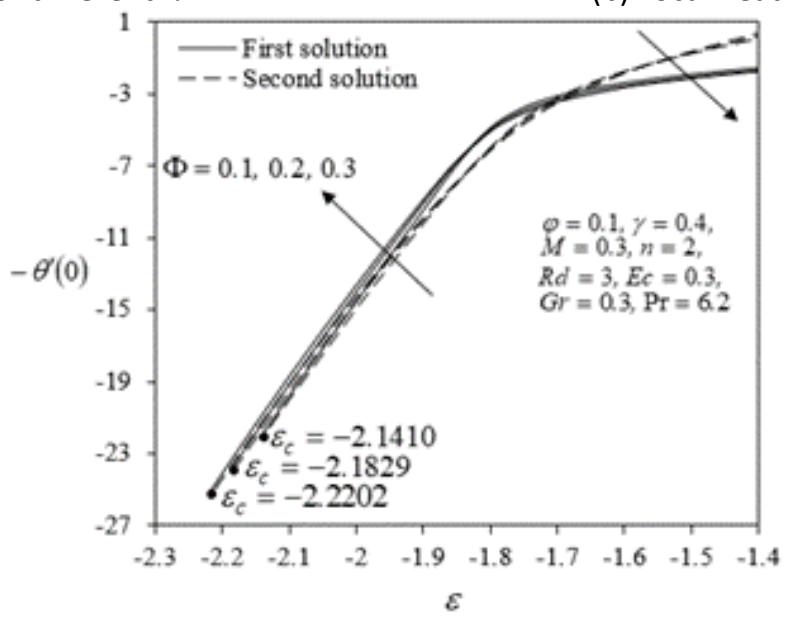

(c) Local heat flux for different $\Phi$

Fig. 4. Variation of local heat flux with $\varepsilon$ for some values of $n, E c$ and $\Phi$

The effect of different types of nanoparticles with nanoparticle volume fraction $\varphi$ in the range of $0<\varphi<0.2$ towards skin friction coefficient $C_{f} R e_{x^{\frac{1}{2}}}$ and local Nusselt number $N u_{x} R e_{x}^{-\frac{1}{2}}$ are presented in Figures 5. The stretching case has been considered in this figure and from the observation, Copper has the highest skin friction coefficient and local Nusselt number compared to 
Alumina and Titania. Moreover, increases the volume of those three types of nanoparticles in water, resulted to increase the skin friction coefficient as well as the heat transfer rate.

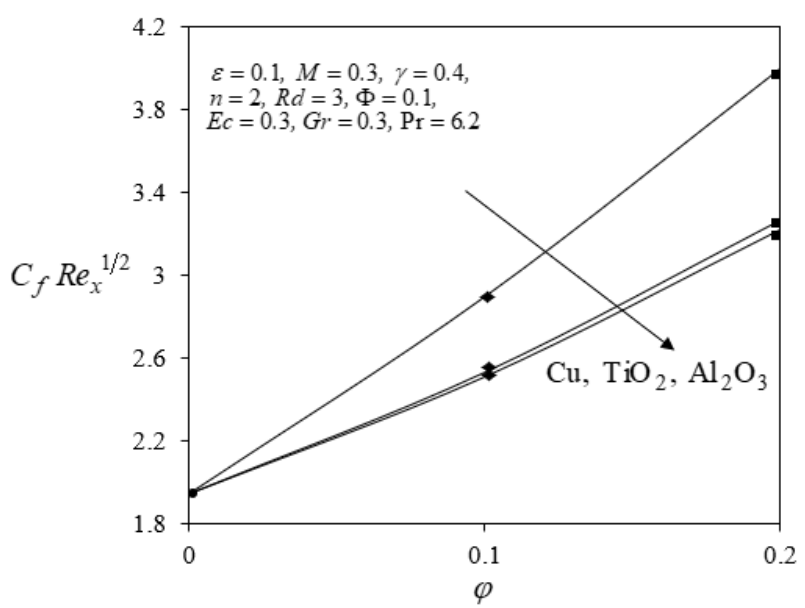

(a) Skin friction coefficients of different nanoparticles

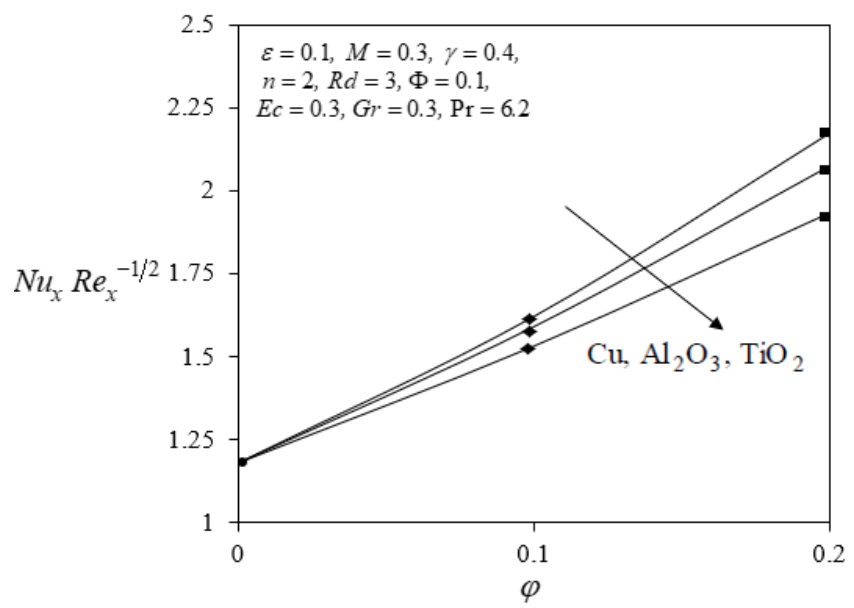

(b) Local Nusselt numbers of different nanoparticles

Fig. 5. Variation of skin friction coefficients and local Nusselt numbers against $\varphi$ for different nanoparticles

Figure 6 reflects the effects of curvature parameter $\gamma$, magnetic parameter $M$, heat generation parameter $\Phi$ and Eckert number on local Nusselt number with some values of $\varphi$. As the curvature parameter between the fluid flow and the surface become higher, the local Nusselt number is decreased and indicates that transferring heat process at the surface is slower with the higher value of $\gamma$. The same situation happened for enhancement values of $M, \Phi$ and $E c$. The higher estimation value of $M, \Phi$ and $E c$ decreased the local Nusselt number as the nanoparticle volume fraction $\varphi$ increase when the surface is shrunk leads to slower the heat transfer.

The variations of velocity and temperature profiles can be seen in Figure 7 to 9 for different nanoparticles, as well as different values of $\varphi, \gamma, R d, \Phi$ and $E c$. All the figures satisfy the boundary conditions asymptotically. We also notice that the boundary layer thickness of the second solution is thicker than the first solution for the dual velocity and temperature profiles shown. The momentum and thermal boundary layer of Copper gives the highest value of velocity compared to Alumina and Titania, as seen in Figure 7. This indicates that Copper performs better than the other two types of nanoparticles and the lowest performance is Alumina. Figure 8 shows the dual velocity and temperature profiles for nanoparticle volume fraction $\varphi$, which the first solution found to increase with increases of $\varphi$ and decrease for the second solution. 


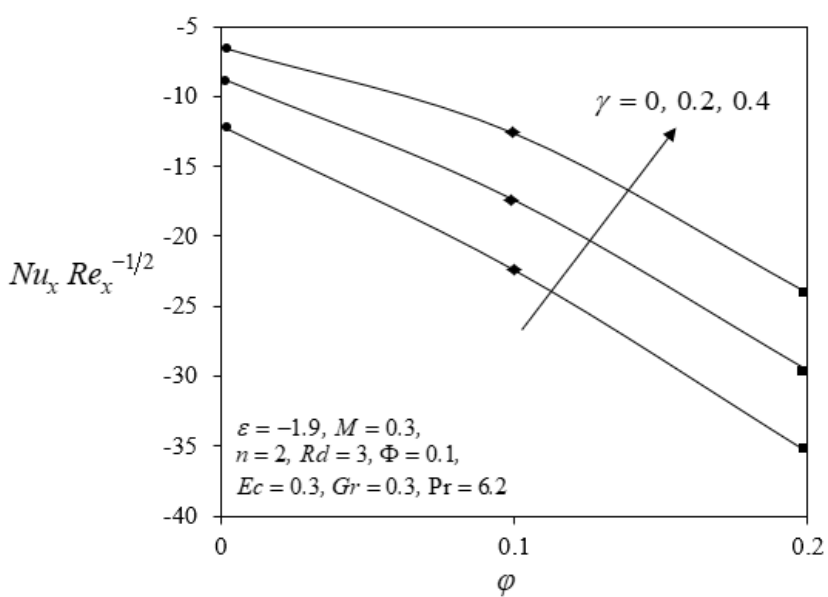

(a) Local Nusselt numbers of $\gamma$

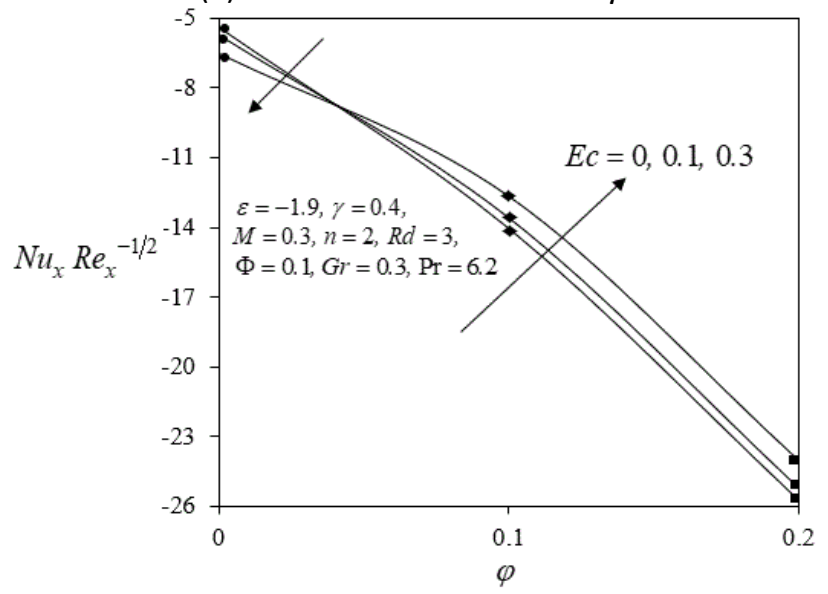

(c) Local Nusselt numbers of $E c$

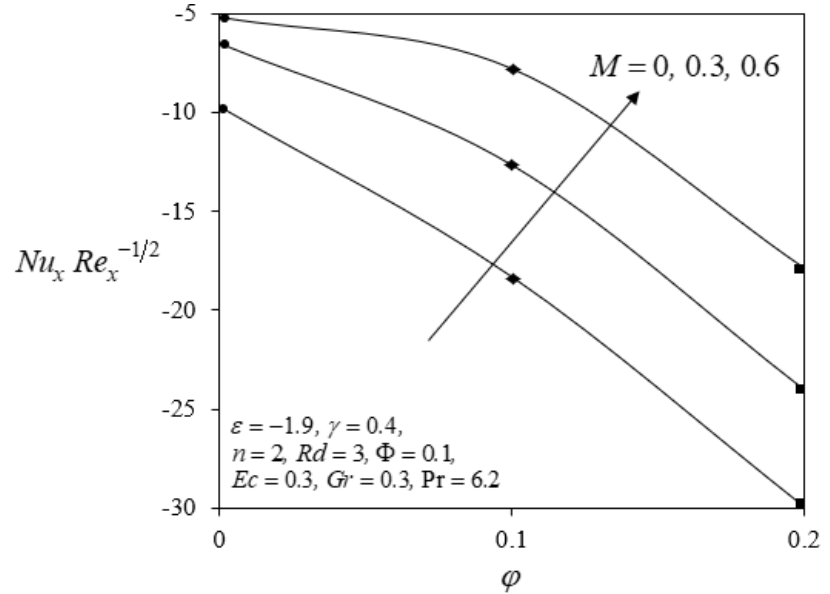

(b) Local Nusselt numbers of $M$

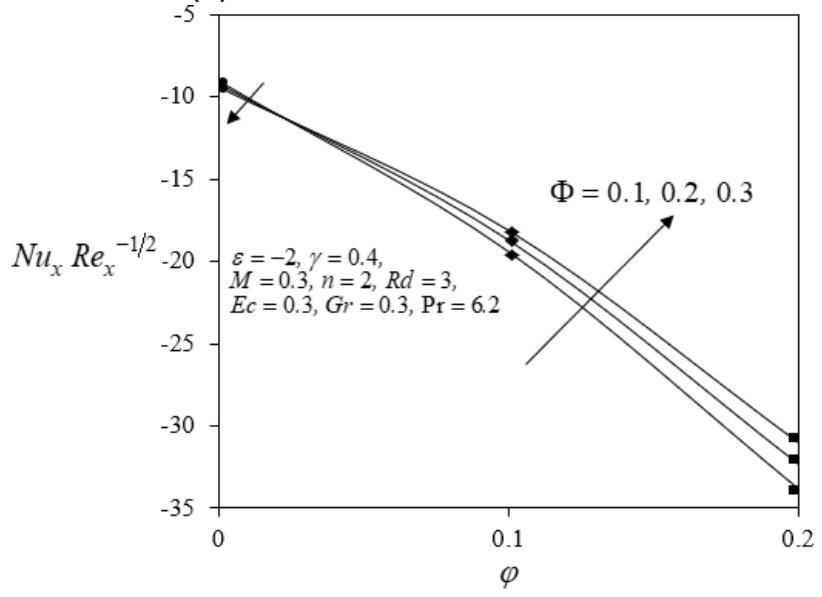

(d) Local Nusselt numbers of $\Phi$

Fig. 6. Variation of local Nusselt numbers against $\varphi$ for some values of $\gamma, M, E c$ and $\Phi$

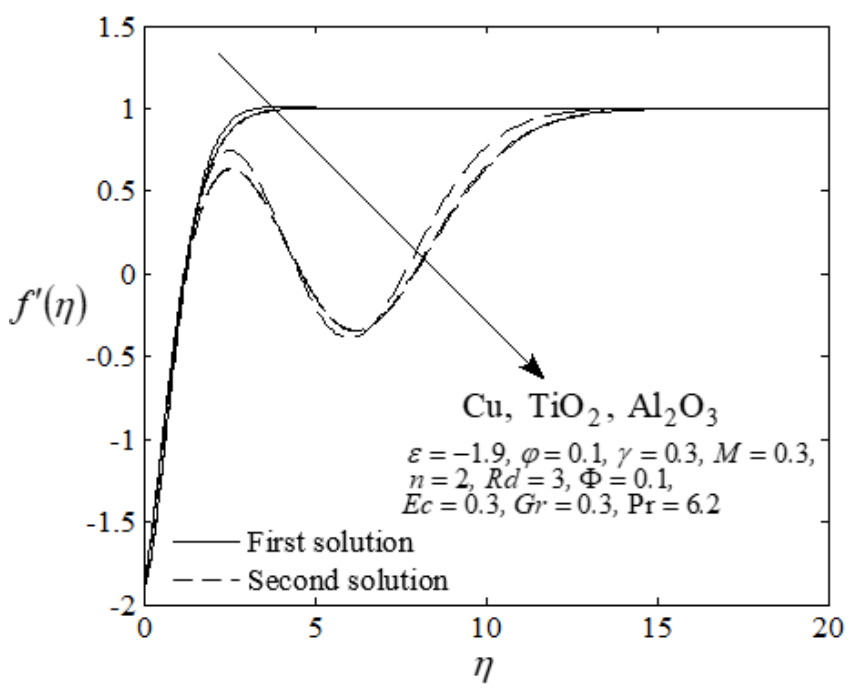

(a) Velocity profiles for different nanoparticles

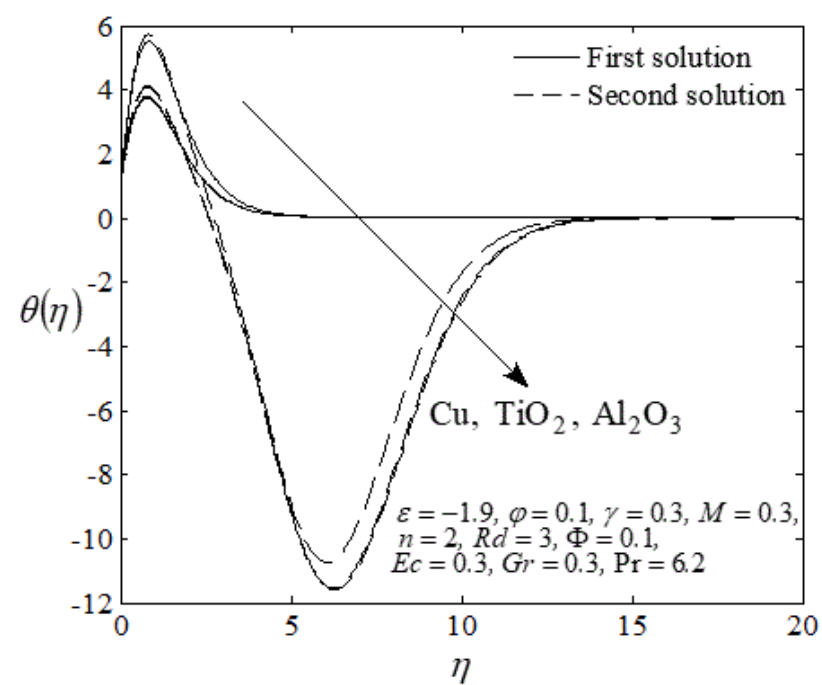

(b) Temperature profiles for different nanoparticles

Fig. 7. Velocity and temperature profiles for different nanoparticles 


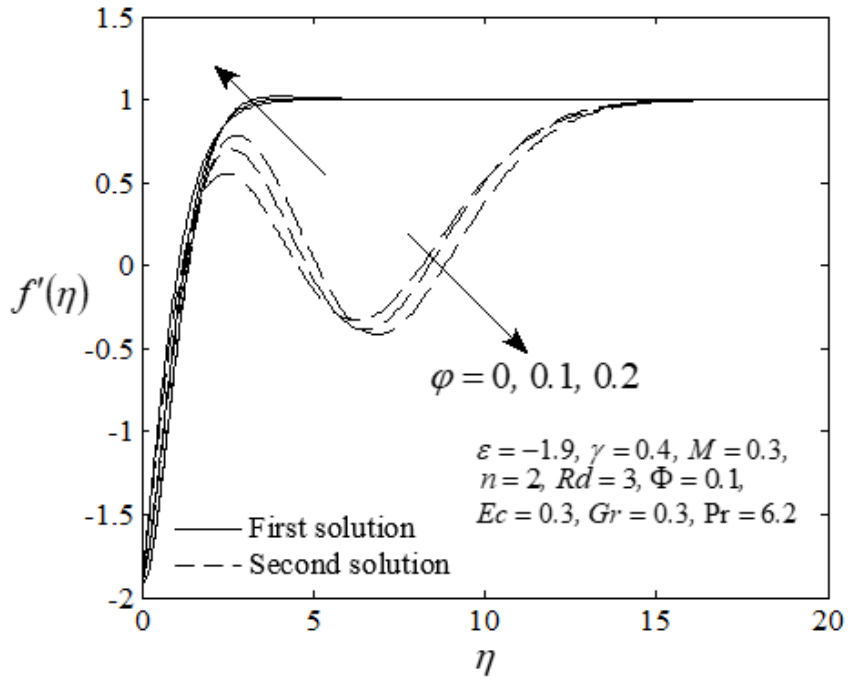

(a) Velocity profiles of $\varphi$

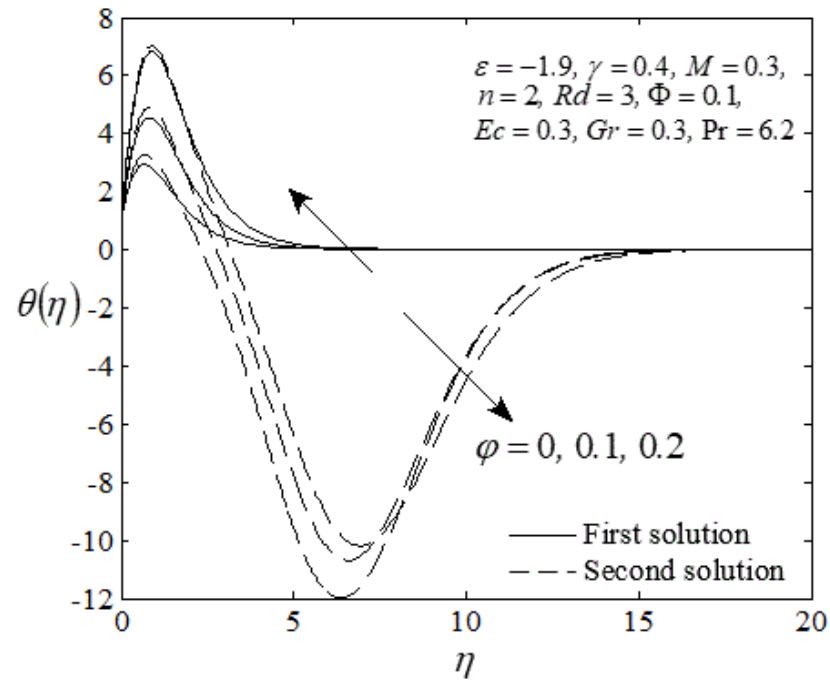

(b) Temperature profiles of $\varphi$

Fig. 8. Velocity and temperature profiles for some values of $\varphi$

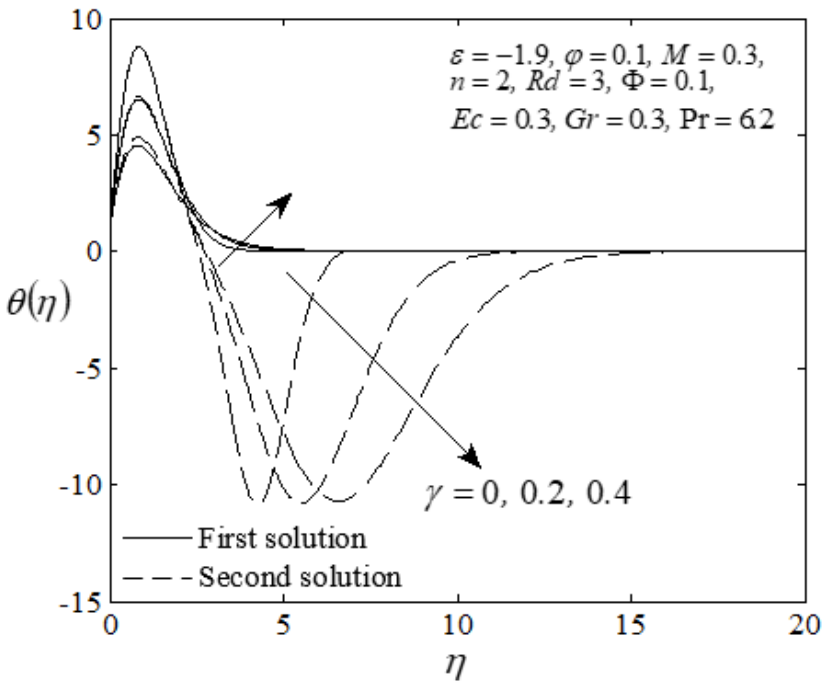

(a) Temperature profiles of $\gamma$

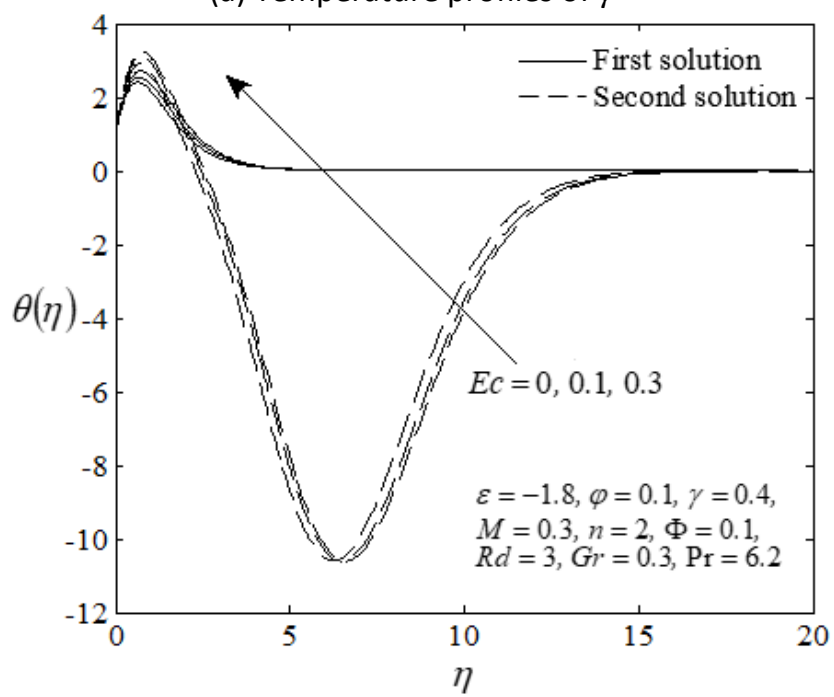

(c) Temperature profiles of $E c$

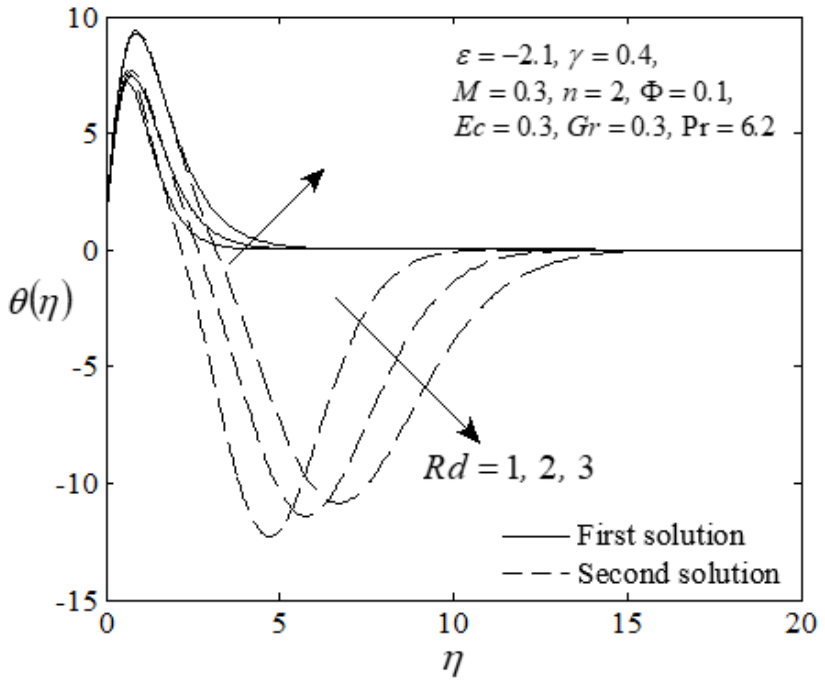

(b) Temperature profiles of $R d$

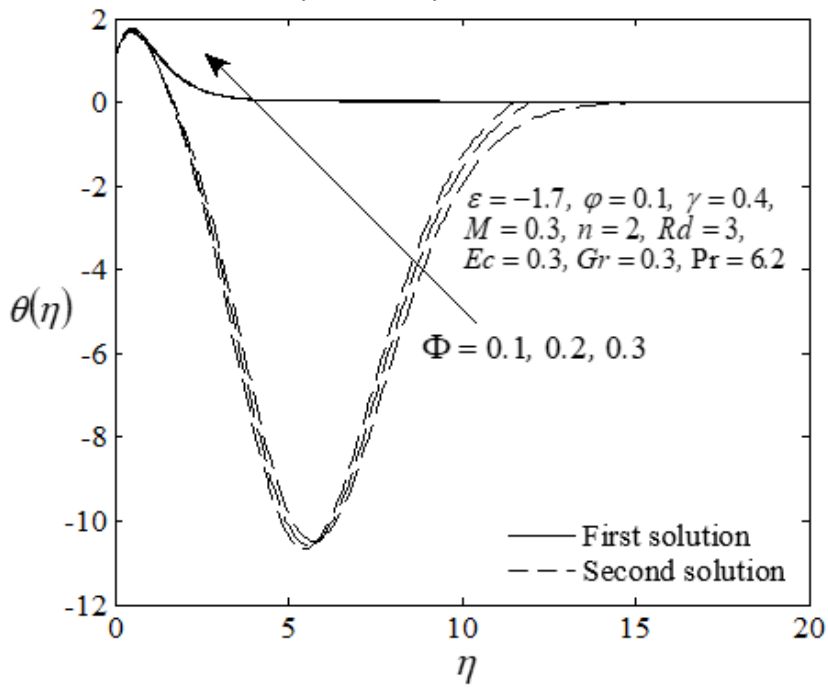

(d) Temperature profiles of $\Phi$

Fig. 9. Temperature profiles for some values of $\gamma, R d, E c$ and $\Phi$ 
As can be seen in Figure 9, the temperature profiles for curvature parameter $\gamma$ and radiation parameter $R d$ initially increase with $\gamma$ and $R d$ for the first solution, but as the $\eta$ become larger, it decreases with $\gamma$ and $R d$. The second solution for both $\gamma$ and $R d$ resulted in a temperature decrease as their values increase. Besides that, the effects of Eckert number $E c$ and heat generation parameter $\Phi$ on temperature profiles is exhibited in Figure 9. The thermal boundary layer increases with the enhancement of $E c$ and $\Phi$. In conclusion, the heat generation parameter and Eckert number play an important role to improve the flow performance in temperature.

\section{Conclusions}

The numerical analysis in this study describes the magnetohydrodynamic (MHD) on the stagnation point flow past a nonlinear stretching or shrinking cylinder with viscous dissipation and heat generation effect. The observation from this study can be concluded as below

i. unique and dual solutions exist only at a certain range of stretching or shrinking parameter values avoid excessively large white space borders around your graphics

ii. the range of solution can be widened for higher curvature, magnetic, radiation, and heat generation parameters, as well as Eckert number

iii. increases the nanoparticles volume fraction improve the skin friction coefficient and heat transfer rate for different nanoparticles

iv. curvature and magnetic parameters have the tendency to increase the shear stress and heat flux

v. enhancement of the heat transfer rate can be done by increase the values of the magnetic parameter, curvature parameter, heat generation parameter, and Eckert number

vi. Copper gives the highest value of velocity and temperature compared to Titania and Alumina

vii. temperature enhances for larger value of heat generation parameter and Eckert number

\section{Acknowledgement}

The authors really appreciate the funding provided for this project by Universiti Putra Malaysia through the Fundamental Research Grant Scheme.

\section{References}

[1] Crane, Lawrence J. "Boundary layer flow due to a stretching cylinder." Zeitschrift für angewandte Mathematik und Physik ZAMP 26, no. 5 (1975): 619-622. https://doi.org/10.1007/BF01594034

[2] Wang, Ch Y. "Fluid flow due to a stretching cylinder." The Physics of fluids 31, no. 3 (1988): $466-468$. https://doi.org/10.1063/1.866827

[3] Ishak, Anuar, Roslinda Nazar, and Ioan Pop. "Magnetohydrodynamic (MHD) flow and heat transfer due to a stretching cylinder." Energy Conversion and Management 49, no. $11 \quad$ (2008): 3265-3269. https://doi.org/10.1016/i.enconman.2007.11.013

[4] Ishak, Anuar, Roslinda Nazar, and loan Pop. "Uniform suction/blowing effect on flow and heat transfer due to a stretching cylinder." Applied Mathematical Modelling 32, no. $10 \quad$ (2008): 2059-2066. https://doi.org/10.1016/i.apm.2007.06.036

[5] Ishak, A., and R. Nazar. "Laminar boundary layer flow along a stretching cylinder." European Journal of Scientific Research 36, no. 1 (2009): 22-29.

[6] Bachok, Norfifah, and Anuar Ishak. "Flow and heat transfer over a stretching cylinder with prescribed surface heat flux." Malaysian Journal of Mathematical Sciences 4, no. 2 (2010): 159-169.

[7] Wang, C. Y., and Chiu-On Ng. "Slip flow due to a stretching cylinder." International Journal of Non-Linear Mechanics 46, no. 9 (2011): 1191-1194. https://doi.org/10.1016/j.ijnonlinmec.2011.05.014 
[8] Mukhopadhyay, Swati. "MHD boundary layer slip flow along a stretching cylinder." Ain Shams Engineering Journal 4, no. 2 (2013): 317-324. https://doi.org/10.1016/j.asej.2012.07.003

[9] Khan, Muhammad ljaz, Muhammad Tamoor, Tasawar Hayat, and Ahmed Alsaedi. "MHD boundary layer thermal slip flow by nonlinearly stretching cylinder with suction/blowing and radiation." Results in Physics 7 (2017): 12071211. https://doi.org/10.1016/i.rinp.2017.03.009

[10] Lok, Y. Y., and I. Pop. "Wang's shrinking cylinder problem with suction near a stagnation point." Physics of Fluids 23, no. 8 (2011): 083102. https://doi.org/10.1063/1.3624697

[11] Zaimi, WMKA Wan, Anuar Ishak, and Ioan Pop. "Unsteady viscous flow over a shrinking cylinder." Journal of King Saud University-Science 25, no. 2 (2013): 143-148. https://doi.org/10.1016/i.jksus.2012.11.005

[12] Marinca, Vasile, and Remus-Daniel Ene. "Dual approximate solutions of the unsteady viscous flow over a shrinking cylinder with Optimal Homotopy Asymptotic Method." Advances in Mathematical Physics 2014 (2014). https://doi.org/10.1155/2014/417643

[13] Mishra, Upendra, and Gurminder Singh. "Dual solutions of mixed convection flow with momentum and thermal slip flow over a permeable shrinking cylinder." Computers \& Fluids 93 (2014): 107-115. https://doi.org/10.1016/i.compfluid.2014.01.012

[14] Awaludin, Izyan Syazana, Rokiah Ahmad, and Anuar Ishak. "On the stability of the flow over a shrinking cylinder with prescribed surface heat flux." Propulsion and Power Research 9, no. 2 (2020): 181-187. https://doi.org/10.1016/i.jppr.2020.03.001

[15] Najib, Najwa, Norfifah Bachok, Norihan Md Arifin, and Anuar Ishak. "Stagnation point flow and mass transfer with chemical reaction past a stretching/shrinking cylinder." Scientific reports 4, no. 1 (2014): 1-7. https://doi.org/10.1038/srep04178

[16] Merkin, J. H., N. Najib, N. Bachok, A. Ishak, and I. Pop. "Stagnation-point flow and heat transfer over an exponentially stretching/shrinking cylinder." Journal of the Taiwan Institute of Chemical Engineers 74 (2017): 6572. https://doi.org/10.1016/i.jtice.2017.02.008

[17] Abu-Nada, E., Z. Masoud, and A. Hijazi. "Natural convection heat transfer enhancement in horizontal concentric annuli using nanofluids." International Communications in Heat and Mass Transfer 35, no. 5 (2008): 657-665. https://doi.org/10.1016/j.icheatmasstransfer.2007.11.004

[18] Qasim, Muhammad, Zafar Hayat Khan, Waqar Ahmad Khan, and Inayat Ali Shah. "MHD boundary layer slip flow and heat transfer of ferrofluid along a stretching cylinder with prescribed heat flux." PloS one 9, no. 1 (2014): e83930. https://doi.org/10.1371/journal.pone.0083930

[19] Imtiaz, Maria, Tasawar Hayat, and Ahmed Alsaedi. "Mixed convection flow of Casson nanofluid over a stretching cylinder with convective boundary conditions." Advanced Powder Technology 27, no. 5 (2016): 2245-2256. https://doi.org/10.1016/j.apt.2016.08.011

[20] Bilal, M., M. Sagheer, and S. Hussain. "Numerical study of magnetohydrodynamics and thermal radiation on Williamson nanofluid flow over a stretching cylinder with variable thermal conductivity." Alexandria engineering journal 57, no. 4 (2018): 3281-3289. https://doi.org/10.1016/i.aej.2017.12.006

[21] Hayat, Tasawar, Madiha Rashid, Ahmed Alsaedi, and Saleem Asghar. "Nonlinear convective flow of Maxwell nanofluid past a stretching cylinder with thermal radiation and chemical reaction." Journal of the Brazilian Society of Mechanical Sciences and Engineering 41, no. 2 (2019): 86. https://doi.org/10.1007/s40430-019-1576-3

[22] Mishra, Ashish, and Manoj Kumar. "Velocity and thermal slip effects on MHD nanofluid flow past a stretching cylinder with viscous dissipation and Joule heating." SN Applied Sciences 2, no. 8 (2020): 1-13. https://doi.org/10.1007/s42452-020-3156-7

[23] Abbas, Nadeem, S. Nadeem, Anber Saleem, M. Y. Malik, Alibek Issakhov, and Fahd M. Alharbi. "Models base study of inclined MHD of hybrid nanofluid flow over nonlinear stretching cylinder." Chinese Journal of Physics 69 (2021): 109-117. https://doi.org/10.1016/i.cjph.2020.11.019

[24] Omar, Noor Syamimi, Norfifah Bachok, and Norihan Md Arifin. "Stagnation point flow over a stretching or shrinking cylinder in a copper-water nanofluid." Indian Journal of Science and Technology 8, no. 31 (2015): 1-7. https://doi.org/10.17485/ijst/2015/v8i31/85405

[25] Abu Bakar, Nor Ashikin, Norfifah Bachok, and Norihan Md Arifin. "Boundary layer stagnation-point flow over a stretching/shrinking cylinder in a nanofluid: A stability analysis." Indian Journal of Pure \& Applied Physics (IJPAP) 57, no. 2 (2019): 106-117.

[26] Adnan, Nurul Shahirah Mohd, Ahmad Nazri Mohamad Som, Norihan Md Arifin, Norfifah Bachok, Fadzilah Md Ali, and Yong Faezah Rahim. "A Stability Analysis of Boundary Layer Stagnation-Point Slip Flow and Heat Transfer towards a Shrinking/Stretching Cylinder over a Permeable Surface." CFD Letters 12, no. 11 (2020): 97-105. https://doi.org/10.37934/cfdl.12.11.97105

[27] Zaimi, Khairy, Anuar Ishak, and loan Pop. "Unsteady flow of a nanofluid past a permeable shrinking cylinder using Buongiorno's model." Sains Malaysiana 46, no. 9 (2017): 1667-1674. https://doi.org/10.17576/jsm-2017-4609-40 
[28] Waini, Iskandar, Anuar Ishak, and loan Pop. "Hybrid nanofluid flow towards a stagnation point on a stretching/shrinking cylinder." Scientific Reports 10, no. 1 (2020): 1-12. https://doi.org/10.1038/s41598-02066126-2

[29] Khashi'ie, Najiyah Safwa, Norihan M. Arifin, John H. Merkin, Rusya Iryanti Yahaya, and loan Pop. "Mixed convective stagnation point flow of a hybrid nanofluid toward a vertical cylinder." International Journal of Numerical Methods for Heat \& Fluid Flow (2021). https://doi.org/10.1108/HFF-11-2020-0725

[30] Ullah, Imran, Tawfeeq Abdullah Alkanhal, Sharidan Shafie, Kottakkaran Sooppy Nisar, Ilyas Khan, and Oluwole Daniel Makinde. "MHD slip flow of Casson fluid along a nonlinear permeable stretching cylinder saturated in a porous medium with chemical reaction, viscous dissipation, and heat generation/absorption." Symmetry 11, no. 4 (2019): 531. https://doi.org/10.3390/sym11040531

[31] Suleman, Muhammad, Muhammad Ramzan, Shafiq Ahmad, and Dianchen Lu. "Numerical simulation for homogeneous-heterogeneous reactions and Newtonian heating in the silver-water nanofluid flow past a nonlinear stretched cylinder." Physica Scripta 94, no. 8 (2019): 085702. https://doi.org/10.1088/1402-4896/ab03a8

[32] Oztop, Hakan F., and Eiyad Abu-Nada. "Numerical study of natural convection in partially heated rectangular enclosures filled with nanofluids." International journal of heat and fluid flow 29, no. 5 (2008): 1326-1336. https://doi.org/10.1016/i.ijheatfluidflow.2008.04.009

[33] Wang, C. Y. "Stagnation flow towards a shrinking sheet." International Journal of Non-Linear Mechanics 43, no. 5 (2008): 377-382. https://doi.org/10.1016/j.ijnonlinmec.2007.12.021

[34] Bhatti, Muhammad Mubashir, M. Ali Abbas, and Mohammad Mehdi Rashidi. "A robust numerical method for solving stagnation point flow over a permeable shrinking sheet under the influence of MHD." Applied Mathematics and Computation 316 (2018): 381-389. https://doi.org/10.1016/i.amc.2017.08.032 